\title{
PENILAIAN FAKTOR FISIK LINGKUNGAN KERJA DI RUANG RAWAT INAP KELAS TIGA RUMAH SAKIT PERTAMINA CILACAP TAHUN 2016
}

\author{
Dika Kristiana $^{\text {1) }}$, Zaeni Budiono ${ }^{2)}$ \\ Jurusan Kesehatan Lingkungan, Politeknik Kesehatan Kemenkes Semarang, \\ Jl.Raya Baturaden KM 12 Purwokerto, Indonesia
}

\begin{abstract}
Abstrak
Rumah Sakit adalah salah satu tempat kerja yang mempunyai risiko bahaya kesehatan, mudahnya terjangkit penyakit. Salah satu faktor yang dapat mempengaruhi, yaitu faktor fisik lingkungan kerja, apabila tidak segera dilakukan upaya penanggulangan akan mengakibatkan penyakit akibat kerja, seperti leukimia. Tujuan penelitian ini adalah untuk mengetahui kualitas nilai faktor fisik lingkungan kerja di ruang rawat inap kelas tiga Rumah Sakit Pertamina Cilacap.Metode penelitian menggunakan penelitian deskriptif yang menggambarkan tentang faktor fisik lingkungan kerja di ruang rawat inap kelas tiga Rumah Sakit Pertamina Cilacap. Pengambilan data dilakukan dengan cara observasi dan pengukuran.Hasil pengukuran lingkungan fisik kerja terhadap intensitas suara, pencahayaan, suhu dan kelembaban di 16 kamar yang diukur tidak memenuhi syarat. Intensitas suara tertinggi terdapat di ruang 106 dan terendah di ruang 117. Intensitas pencahayaan tertinggi terdapat di ruang 211 kamar B dan terendah di ruang 106 kamar B. Suhu tertinggi terdapat di ruang 211 kamar D dan ruang 117 kamar A dan B, suhu terendah berada di ruang 211 kamar B dan ruang 106 kamar A dan B. Kelembaban tertinggi berada di ruang 211 kamar A,B dan D serta ruang 212 kamar B, kelembaban terendah berada di ruang 214 kamar A, B, C dan B.Berdasarkan uraian diatas dapat disimpulkan nilai faktor fisik lingkungan kerja di ruang rawat inap kelas tiga Rumah Sakit Pertamina Cilacap tidak memenuhi syarat. Disarankan agar pihak Rumah Sakit dapat meningkatkan kualitas lingkungan fisik Rumah Sakit.
\end{abstract}

Kata kunci: Lingkungan Fisik Kerja, Ruang Rawat Inap Kels Tiga

\begin{abstract}
Hospital is one of risk for workplace health hazards, ease of contracting the disease. One of the factors that can influence, namely physical factors working environment, if not immediate reduction efforts will result in occupational diseases, such as leukemia. The purpose of this study is to investigate the value of physical factors in the work environment class inpatient hospital three Pertamina Cilacap.The research method using descriptive research that describes the physical factors in the work environment class inpatient hospital three Pertamina Cilacap. Data were collected by means of observation and measurement.The measurement results of the physical environment working against the intensity of sound, lighting, temperature and humidity in the room measured 16 are not eligible. Sound intensity is highest in room 106 and the lowest in room 117. The illumination intensity is highest in room $211 \mathrm{~B}$ and the lowest room in room 106 room B. The temperature is highest in room $D$ room 211 and room 117 rooms $A$ and $B$, the lowest temperature was in room B room 211 and room 106 rooms $A$ and $B$. The highest humidity was in room 211 rooms $A, B$ and $D$ as well as room 212 room $B$, the lowest humidity was in room 214 rooms $A, B, C$ and B.Based on the description above can be concluded value of physical factors in the work environment class inpatient hospital three Pertamina Cilacap ineligible. It is recommended that the hospital can improve the quality of the physical environment Hospital
\end{abstract}

Keywords: Work Physical Environment, patient wards Kels Three

\section{PENDAHULUAN}

Undang-undang No.36 tahun 2009 tentang kesehatan, khususnya tentang kesehatan kerja, bahwa upaya kesehatan kerja harus diselenggarakan di semua tempat, khususnya tempat kerja yang mempunyai risiko bahaya kesehatan, mudah terjangkit penyakit

1) Email : dikakristiana66@yahoo.co.id

2) Email : pakzaeni@gmail.com 
atau mempunyai karyawan paling sedikit 10 orang. Dalam berkembangnya teknologi dibidang kesehatan, hususnya rumah sakit dapat menjadi sumber penyakit akibat kerja dan resiko kecelakaan akibat kerja. Faktor yang dapat mempengaruhinya yaitu faktor fisik lingkungan kerja.

Rumah Sakit Pertamina Cilacap merupakan rumah sakit yang masuk dalam katagori Madya dengan kelas rumah sakit adalah rumah sakit umum kelas D, yang disiapkan untuk mendukung kegiatan operasional Renifery Unit IV Pertamina di Cilacap dan sekitarnya. Rumah Sakit Pertamina memiliki jumlah karyawan 213 orang. Ruang rawat inap rumah sakit Pertamina dibagi menjadi lima kelas, yaitu kelas VVIP, VIP, kelas satu, kelas dua, dan kelas tiga yang terdapat di tiga lantai yaitu lantai satu, dua dan tiga. Dengan jumlah kamar tidur 50 ruang. BOR Rumah Sakit Pertamina Cilacap di tahun 2015 mencapai $37,46 \%$.Tujuan penelitian adalah untuk mengetahui hubungan iklim kerja dengan kelelahan pada tenaga kerja bagian produksi di PT. Hatapan Jaya Globalindo Tahun 2016.

Ruang rawat inap kelas tiga merupakan salah satu ruang yang digunakan untuk proses pemulihan pasien dan ruang beraktivitas pekerja medis. Ruang rawat inap kelas tiga yang terdapat di rumah sakit Pertamina Cilacap berjumlah 16 kamar yang terbagi di lima ruang, dengan setiap ruang terdapat empat kamar tidur dan dua kamar tidur.

Peneliti mencoba untuk mengadakan penelitian di ruang rawat inap kelas tiga karena peneliti ingin mengetahui nilai intensitas suara, pencahayaan, suhu dan kelembaban. Berdasarkan hal tersebut peneliti mengadakan penelitian dengan judul "Penilaian Faktor Fisik Ligkungan Kerja di Ruang Rawat Inap Kelas Tiga Rumah Sakit Pertamina Cilacap Tahun 2016".

\section{BAHAN DAN METODE}

Jenis penelitian deskriptif dengan pendekatan evaluasi, dimaksudkan untuk menggambarkan tentang kondisi yang sesungguhnya sesuai data yang diperoleh tentang pengukuran faktor fisik lingkungan kerja di ruang rawat inap kelas tiga Rumah Sakit Pertamina Cilacap (RSPC).menggambarkan tiap variabel dan analisis bivariate menggunakan uji regresi sederhana.

\section{HASIL DAN PEMBAHASAN Intensitas Suara}

Hasil pengukuran intensitas suara pada lima ruang di ruang rawat inap kelas tiga Rumah Sakit Pertamina Cilacap pada tabel 3.1

Tabel 3.1 intensitas Suara di Ruang Rawat Inap Kelas Tiga Rumah Sakit Pertamina Cilacap

\begin{tabular}{llccc}
\hline No & $\begin{array}{c}\text { lokasi } \\
\text { pengukuran }\end{array}$ & $\begin{array}{c}\text { hasil } \\
\text { pengukuran }\end{array}$ & Satuan & Ket. \\
\hline 1 & R. 211 & 52,86 & dB & TMS \\
\hline
\end{tabular}

\begin{tabular}{lllll}
\hline 2 & R. 212 & 53,56 & dB & TMS \\
3 & R. 214 & 52,00 & dB & TMS \\
4 & R. 117 & 51,55 & dB & TMS \\
5 & R. 106 & 54,41 & dB & TMS \\
\hline
\end{tabular}

Keterangan : MS: Memenuhi syarat

TMS: Tidak memenuhi syarat

Hasil pengukuran intensitas suara pada 5 ruang di rawat inap kelas tiga RS Pertamina Cilacap jika dibandingkan dengan KepMenKes RI no.1204 tahun 2002 tentang kesehatan lingkungan rumah sakit tidak memenuhi syarat. Standar nilai yang terdapat di peraturan adalah $45 \mathrm{~dB}$ pada saat pasien tidak tidur.

Hasil dari pengukuran tersebut dapat dipengaruhi oleh sumber bunyi dari aktifitas yang ada di rumah sakit. Suara mesin boiler, mesin incenerator dan suara air handling unit (AC central) juga mempengaruhi intensitas suara yang ada di ruang rawat inap, karena saat melakukan pengukuran bertepatan dengan kegiatan mesin yang sedang beroprasi, selain itu hembusan angin laut dan suara ombak juga mempengaruhinya.

\section{Pencahayaan}

Hasil pengukuran pencahayaan pada 16 kamar di ruang rawat inap kelas tiga RS Pertamina Cilacap dapat dijelaskan pada tabel 3.2.

Tabel 3.2 Pencahayaan di Ruang Rawat Inap Kelas Tiga RS Pertamina Cilacap

\begin{tabular}{clrl}
\hline Ruang & Kamar & Hasil (Lux) & Ket. \\
\hline 211 & A & 553,00 & TMS \\
& B & $1.018,00$ & TMS \\
& C & 132,00 & MS \\
& D & 132,00 & MS \\
& & & \\
212 & A & 605,75 & TMS \\
& B & 682,25 & TMS \\
& C & 130,75 & MS \\
& D & 71,25 & TMS \\
& & & \\
214 & A & 431,75 & TMS \\
& B & 517,50 & TMS \\
& C & 130,75 & MS \\
& D & 132,00 & MS \\
\hline \multirow{2}{*}{117} & A & 457,20 & TMS \\
& B & 138,00 & MS \\
& A & 58.50 & TMS \\
& B & 33,00 & TMS \\
\hline
\end{tabular}

Keterangan : MS: Memenuhi syarat

TMS: Tidak memenuhi syarat

Pengukuran pencahayaan pada 16 kamar di ruang rawat inap kelas tiga RS Pertamina Cilacap jika dibandingkan dengan KepMenKes RI no.1204 tahun 2002 tentang kesling rumah sakit, 10 kamar tidak memenuhi syarat dan 6 kamar memenuhi syarat. Standar nilai yang terdapat diperaturan adalah 100200 lux. 
hasil pengukuran yang didapat melebihi standar diakibatkan karena pada saat melakukan pengukuran, bertepatan dengan cahaya matahari begitu panas dan ruangan rawat inap sebagian terbuat dari kaca yang dilapisi gorden berwarna putih dan tembok yang berwarna putih sehingga membuat cahaya semakin terang. Ruangan yang intensitas pencahayannya memenuhi syarat atau kurang dari nilai yang ditentukan, diakibatkan karena tidak ada cahaya yang masuk pada siang hari. Cahaya tersebut tidak dapat masuk karena terhalang oleh dinding atau kamar di sebelahnya. Posisi pemasangan lampu yang menempel pada tembok dan hanya terdapat satu deret lampu juga dapat mempengaruhi keadaan cahaya di ruangan. Kondisi pencahayaan yang seperti ini dapat mengganggu pekerja saat melaksanakan tugas dan dapat mengganggu istirahat pasien karena terlalu silaunya cahaya.

\section{Suhu dan Kelembaban}

Hasil pengukuran Suhu pada 16 kamar di ruang rawat inap kelas tiga RS Pertamina Cilacap dapat dijelaskan pada tabel 3.3.

Tabel 3.3 Pengukuran Suhu di Ruang Rawat Inap Kelas Tiga RS Pertamina Cilacap.

\begin{tabular}{clcc}
\hline Ruang & Kamar & Hasil $\left({ }^{\circ} \mathrm{C}\right)$ & Ket. \\
\hline 211 & A & 27,00 & TMS \\
& B & 26,00 & TMS \\
& C & 29,00 & TMS \\
& D & 27,00 & TMS \\
& A & 28,00 & TMS \\
& B & 27,00 & TMS \\
& C & 28,00 & TMS \\
& D & 29,00 & TMS \\
& A & 28,00 & TMS \\
& B & 28,00 & TMS \\
& C & 28,00 & TMS \\
& D & 28,00 & TMS \\
& A & 29,00 & TMS \\
& B & 29,00 & TMS \\
& A & 26,00 & TMS \\
& B & 26,00 & TMS \\
\hline
\end{tabular}

Keterangan : MS: Memenuhi syarat

TMS: Tidak memenuhi syarat

Pengukuran suhu pada 16 kamar di ruang rawat inap kelas tiga RS Pertamina Cilacap jika dibandingkan dengan KepMenKes RI no.1204 tahun 2002 tentang kesling rumah sakit, tidak memenuhi syarat. Standar nilai yang terdapat diperaturan adalah 22-24 ${ }^{\circ} \mathrm{C}$.

Hasil pengukuran Kelembaban pada 16 kamar di ruang rawat inap kelas tiga RS Pertamina Cilacap dapat dijelaskan pada tabel 3.4.

Tabel 3.4 Pengukuran Kelembaban di Ruang Rawat Inap Kelas Tiga RS Pertamina Cilacap.

\begin{tabular}{llll}
\hline Ruang & Kamar & Hasil $\left({ }^{\%}\right)$ & Ket. \\
\hline
\end{tabular}

\begin{tabular}{|c|c|c|c|}
\hline \multirow{4}{*}{211} & A & 92 & TMS \\
\hline & B & 92 & TMS \\
\hline & C & 78 & TMS \\
\hline & $\mathrm{D}$ & 92 & TMS \\
\hline \multirow[t]{4}{*}{212} & A & 85 & TMS \\
\hline & B & 92 & TMS \\
\hline & $\mathrm{C}$ & 70 & TMS \\
\hline & $\mathrm{D}$ & 85 & TMS \\
\hline \multirow[t]{4}{*}{214} & A & 70 & TMS \\
\hline & B & 70 & TMS \\
\hline & C & 70 & TMS \\
\hline & $\mathrm{D}$ & 70 & TMS \\
\hline \multirow[t]{2}{*}{117} & A & 83 & TMS \\
\hline & B & 83 & TMS \\
\hline \multirow[t]{2}{*}{106} & A & 82 & TMS \\
\hline & B & 82 & TMS \\
\hline
\end{tabular}

Keterangan : MS: Memenuhi syarat

TMS: Tidak memenuhi syarat

Pengukuran kelembaban pada 16 kamar di ruang rawat inap kelas tiga RS Pertamina Cilacap jika dibandingkan dengan KepMenKes RI no.1204 tahun 2002 tentang kesling rumah sakit, tidak memenuhi syarat. Standar nilai yang terdapat diperaturan adalah 45-60\%.

Hasil pengukuran tersebut dipengaruhi oleh cuaca yang panas serta pemasangan AC yang central. Sehingga penghuni ruangan tidak dapat menaikan atau menurunkan suhu ruangan, karena tombol pengurang dan penambah suhu berada di beberapa titik. Keadaan geografis juga mempengaruhi suhu, semakin tinggi suhu luar, maka semakin tinggi juga suhu ruangan. Kelembaban juga dipengaruhi oleh suhu luar dan suhu dalam, semakin tinggi suhu, maka kelembaban juga akan tinggi

\section{SIMPULAN DAN SARAN SIMPULAN}

Hasil pengukuran intensitas suara di lima ruang rawat inap kelas tiga $100 \%$ tidak memenuhi syarat. Standar intensitas suara di ruang rawat menurut KepMenKes RI No.1204 tahun 2002 adalah 45 dB pada saat pasien tidak tidur.

Hasil pengukuran Intensitas pencahayaan di lima ruang rawat inap kelas tiga ada yang memenuhi syarat dan ada yang tidak memenuhi syarat. Lima ruang yang terdiri dari 16 kamar, 37,5\% memenuhi syarat dan $62.5 \%$ tidak memenuhi syarat. Enam kamar yang memenuhi syarat adalah ruang 211 kamar C dan D, ruang 212 kamar C, ruang 214 kamar C dan D, serta ruang 117 kamar B. 10 kamar yang tidak memenuhi syarat antara lain ruang 211 kamar A dan B, ruang 212 kamar A dan B, ruang 214 kamar A dan B, ruang 117 kamar A dan ruang 106 kamar A dan B. Nilai tertinggi terdapat di ruang 211 kamar B dengan nilai 1.018 dan nilai terendah terdapat di ruang 106 kamar B. Menurut KepMenKes RI No. 1204 tahun 2002 standar pecahayaan di ruang rawat inap adalah 100-200 Lux.I

Hasil pengukuran suhu di ruang rawat inap kelas tiga, yang terdiri dari 16 kamar 100\% tidak memenuhi syarat. Hasil pengukuran menunjukan lebih dari 
standar. Hal ini dikarenakan karena pengatur suhu ruangan berada di beberapa titik tidak disetiap kamar atau ruang, karena AC yang dipergunakan adalah $A C$ central sehingga penghuni tidak dapat mengantur suhu ruangan masing-masing. Selain itu keadaan cuaca pada saat pengukuran cukup panas bertepatan dengan teriknya sinar matahari. Suhu tertinggi terdapat di ruang 211 kamar C, ruang 212 kamar D, dan ruang 117 kamar A dan B. Suhu terendah terdapat di ruang 211 kamar B, ruang 106 kamar A dan B. Menurut KepMenKes RI No.1204 tahun 2002 suhu di ruang rawat adalah $22-24{ }^{\circ} \mathrm{C}$.

Hasil pengukuran kelembaban di ruang rawat inap kelas tiga, yang terdiri dari 16 kamar 100\% tidak memenuhi syarat. Hasil pengukuran menunjukan lebih dari nilai yang ditentukan, karenakan suhu yang tinggi maka kelembaban yang ada di ruangan tersebut juga tinggi. Kelembaban tertinggi terdapat di ruang 211 kamar D dan ruang 212 kamar B. Kelembaban terendah terdapat di ruang 214 kamar A, B, C, dan D. Menurut KepMenKes RI No.1204 tahun 2002 kelembaban di ruang rawat inap adalah 45-60\%.

\section{SARAN}

Mengisolasi mesin untuk menurunkan intensitas suara yang disebabkan oleh mesin Boiler dan Incenerator.

Sebaiknya di ruang rawat inap dinding yang sebagian terbuat dari kaca dilapisi gorden warna biru, agar cahaya matahari yang masuk tidak terlalu terang. Pemasangan gorden diberi sekat atau jarak antara gorden dengan kaca.

Menambah kipas angin atau AC di ruangan.

\section{DAFTAR PUSTAKA}

Departemen Kesehatan RI, 2001, Pedoman Teknis Upaya Kesehatan Kerja di Rumah Sakit, Jakarta: DEPKES RI

Gladis Pamela, 2011, Hubungan Faktor Lingkungan Fisik dengan Risiko kecelakaan Kerja di Bagian Produksi PT. Holcim Tbk Pabrik Cilacap tahun 2011, KTI, Purwokerto: Kementrian Kesehatan RI Politeknik Kesehatan Kementrian Kesehatan Semarang Jurusan Kesehatan Lingkungan Purwokerto

Haryono \& Heru Subaris, 2007, Hygiene Lingkungan Kerja, Jogjakarta: Mitra Cendikia press

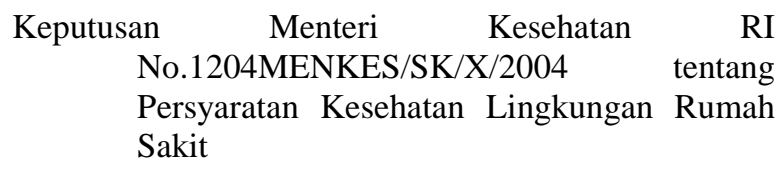

Keputusan Menteri Kesehatan RI No.1405/MENKES/SK/XI/2002 tentang Persyaratan Lingkungan Kerja Perkantoran dan Industri
Keputusan Menteri Kesehatan RI No.432/MENKES/SK/IV/2007 tentang Pedoman Manajemen Kesehatan dan Keselamatan Kerja (K3) di Rumah Sakit.

Peraturan Menteri Kesehatan Republik Indonesia No.340/MENKES/PER/III/2010 tentang Klasifikasi Rumah Sakit

Peraturan Menteri Kesehatan Republik Indonesia No.56 tahun 2014 tentang Klasifikasi dan Perizinan Rumah Sakit

Peraturan Menteri Tenaga Kerja dan Transmigrasi No PER.13/MEN/X/2011 tahun 2011 Tentang Nilai Ambang Batas Faktor Fisika dan Faktor Kimia di Tempat Kerja

Undang-Undang Republik Indonesia No.44 tahun 2009 tentang Rumah Sakit

Undang-Undang Republik Indonesia No.36 tahun 2009 tentang Kesehatan 